\title{
KONTRIBUSI ADVERSITY QUOTIENT DAN SPRITUAL QUOTIENT TERHADAP MANAJEMEN STRESS KERJA GURU SMP NEGERI KECAMATAN BANGKINANG KOTA.
}

\author{
Rina Fitria ${ }^{(1)}$ \\ Isjoni $^{(2)}$ \\ Azhar $^{(3)}$ \\ 1) Post Graduate Student of Riau University \\ 2) Lecturer of Education Management Study Programme PPs University of Riau \\ ${ }^{3)}$ Lecturer of Education Management Study Programme PPs University of Riau
}

\begin{abstract}
The purpose of this study was to analyze the contribution of Adversity Quotient and Spiritual Quotient together to the stress management of the work stress of State Junior High School teachers in the District of Bangkinang Kota. The sample in this study amounted to 92 teachers of SMP Negeri in the District of Bangkinang Kota. Analysis of the data used in the study is simple and multiple regression and correlation. The results of the study explained that adversity quotient has a contribution to the management of teacher work stress with a contribution of $74.4 \%$. In the next test spiritual quotient has a contribution to the management of work stress teachers with a contribution of $73.5 \%$. The results of multiple linear regression tests explain that adversity quotient and spiritual quotient have a contribution to the management of teacher job stress. While the coefficient of determination obtained from the square of the resulting correlation coefficient of $76.2 \%$.
\end{abstract}

Keywords: Adversity Quotient, Spiritual Quotient and Teacher Work Stress Management

\begin{abstract}
ABSTRAK
Tujuan dalam penelitian ini adalah untuk menganalisis kontribusi Adversity Quotient dan Spiritual Quotient secara bersama sama terhadap manajemen stres kerja guru SMP Negeri di Kecamatan Bangkinang Kota. Sampel dalam penelitian ini berjumlah 92 orang guru SMP Negeri di Kecamatan Bangkinang Kota. Analisis data yang digunakan dalam penelitian adalah regresi dan korelasi sederhana serta berganda. Hasil penelitian menjelaskan bahwa adversity quotient memiliki kontribusi terhadap manajemen stres kerja guru dengan kontribusi sebesar $74,4 \%$. Pada pengujian selanjutnya spiritual quotient memiliki kontribusi terhadap manajemen stres kerja guru dengan kontribusi sebesar 73,5\%. Hasil uji regresi linier berganda menjelaskan bahwa adversity quotient dan spiritual quotient memiliki kontribusi terhadap manajemen stres kerja guru. Sementara koefisien determinasi yang diperoleh dari kuadrat dari koefisien korelasi yang dihasilkan sebesar sebesar 76,2\%.
\end{abstract}

Kata Kunci : Adversity Quotient, Spiritual Quotient dan Manajemen Stres Kerja Guru 


\section{PENDAHULUAN}

Menggagas persoalan pendidikan pada dasarnya adalah menggagas persoalan kebudayaan dan peradaban. Secara spesifik gagasan pendidikan akan merambah ke wilayah pembentukan peradaban masa depan, Hal ini dilakukan untuk membantu perkembangan potensi dan kemampuan agar bermanfaat bagi kepentingan hidupnya. Guru juga memiliki kedudukan sebagai figur sentral dalam meningkatkan proses belajar mengajar. Di tangan para gurulah terletak kemungkinan berhasil atau tidaknya pencapaian tujuan belajar mengajar di sekolah, serta di tangan guru pulalah bergantungnya masa depan karir peserta didik yang menjadi tumpuan para orang tua.

\section{Manajemen}

pendidikan merupakan suatu kegiatan untuk mengelola seluruh sumber daya yang ada di dalamnya, baik yang bersifat fisik maupun psikologis. Penting bagi sebuah sekolah agar tidak hanya memperhatikan akan kebutuhan fisik saja bagi sekolahnya, tetapi juga kondisi psikologis sumberdaya manusia yang ada, terutama kesejahteraan para guru. Sistem penilaian yang semakin detail dan rumit, belum lagi sitem pembelajaran kelas yang disajikan per tema. Setiap guru diharuskan untuk dapat menerima dan melaksanakan setiap kebijakan maupun perubahan yang terjadi.

Guru dituntut untuk memiliki AQ yang tinggi, mengingat tugas guru sebagai pendidik dan sebagai model bagi peserta didiknya. Sebagai seorang guru, banyak hambatan yang di hadapi oleh guru tersebut, seperti halnya hambatan dalam meningkatkan prestasi belajar siswa. Seorang guru sebagai pencetak generasi penerus juga harus dapat mengoptimalkan berbagai kecerdasan yang dimilikinya kedalam pembelajaran khususnya kecerdasan spiritual yang merupakan kecerdasan yang lebih dekat dengan pembentukan moral serta prilaku dan hal itu dapat diwujudkan melalui keteladan moral dan budi pekerti. Fakta yang terjadi di lapangan menunjukkan bahwa tuntutan untuk dapat selalu bekerja lebih baik setiap harinya dapat memberikan tekanan bagi guru yang akan menimbulkan stres.

Berdasarkan hasil pra survey yang telah dilakukan dimana banyak faktor yang dapat memicu timbulnya stres didalam bekerja seperti adanya beban kerja yang berlebihan, pimpinan yang kurang bijaksana didalam mengambil sebuah keputusan, pemberian waktu kerja yang tidak sesuai dan terburu-buru, konflik kerja serta masalah pribadi yang di rasakan pada saat berada ditempat kerja. Hal-hal tersebut dapat memicu timbulnya stres pada diri seseorang sehingga akan berdampak terhadap pekerjaan yang akan diselesaikan.

Beban kerja merupakan salah satu faktor yang dapat mempengaruhi terjadinya stres pada guru. Individu cenderung mengalami stres karena terlalu banyak pekerjaan yang harus ia selesaikan dan cenderung sulit/rumit untuk diselesaikan. Akibat adanya stres kerja tersebut yaitu orang menjadi nervous, merasakan kecemasan yang kronis, peningkatan ketegangan pada emosi, proses beriikir dan kondisi fisik individu. Selain itu, sebagai hasil dari adanya stres kerja para guru mengalami beberapa gejala stres yang dapat mengancam dan mengganggu pelaksanaan kerja mereka, seperti : mudah marah dan agresi, tidak dapat relaks, emosi yang tidak stabil, sikap tidak mau bekerja sama, perasaan tidak mampu terlibat,dan kesulitan alam masalah tidur.

Untuk menjaga keamanan dan kenyamanaan kerja, psikologi seseorang juga harus stabil agar terjadi hubungan yang harmonis antara faktor kejiwaan 
serta kondisi yang terjadi. Jadi kita harus memperhatikan secara lebih baik lingkungan yang dapat mempengaruhi psikologi (kejiwaan) seseorang sehingga stres dapat diminimalisir. Oleh karena itulah pentingnya manajemen stres kerja bagi seorang guru. Dengan manajemen stres kerja yang baik, guru dapat mengelola stres yang ada dengan baik. Namun tidak semua guru memiliki adversity quotient dan spiritual qoutient yang sama. Adversity quotient dan spritual quotient memiliki hubungan yang positif

Berdasarkan pada latar belakang maka dapat dirumuskan beberapa masalah pada penelitian ini sebagai berikut : 1) Berapa besar kontribusi adversity quotient terhadap manajemen stress kerja pada guru SMP Negeri Dikecamatan Bangkinang Kota ?. 2) Berapa besar kontribusi spiritual quotient quotient terhadap manajemen stress kerja pada guru SMP Negeri Dikecamatan Bangkinang Kota ?. 3) Berapa besar kontribusi adversity quotient dan spiritual quotient terhadap manajemen stress kerja pada guru SMP Negeri Dikecamatan Bangkinang Kota?

Tujuan penelitian ini adalah sebagai berikut : 1) Untuk mengetahui seberapa besar kontribusi Adversity Quotient terhadap manajemen stres kerja guru SMP Negeri di Kecamatan Bangkinang kota. 2) Untuk mengetahui seberapa besar kontribusi Spiritual Quotient terhadap manajemen stres kerja guru SMP Negeri di Kecamatan Bangkinang kota. 3) Untuk mengetahui seberapa besar kontribusi Adversity Quotient dan Spiritual Quotient secara bersama sama terhadap manajemen stres kerja guru SMP Negeri di Kecamatan Bangkinang kota

\section{KAJIAN TEORITIS \\ 1. Manajemen Srres Kerja}

Menurut Stephen P. Robbins \& Timothy A. Judge (2011) stres adalah suato kondisi dinamis dimana seseorang individu dihadapkan pada peluang, tuntutan atau sumber daya yang terkait dengan apa yang dihasratkan oleh individu itu dan hasilnya dipandang tidak pasti dan penting. Stres lebih sering dikaitkan dengan tuntutan (demand) dan sumber daya (resources). Tuntutan merupakan tanggung jawab, tekanan, kewajiban, dan bahkan ketidakpastian yang dihadapi para individu ditempat kerja. Sumber daya adalah hal-hal (atau benda-benda) yang berada dalam kendali seorang individu yang dapat digunakan untuk memenuhi tuntutan.

Manajemen stres kerja guru adalah suatu tindakan yang dilakukan oleh guru untuk mengontrol sumber stres yang di alaminya agar tidak menimbulkan efek negatif kedepannya. Manajemen stres guru adalah dimana seorang guru melakukan pengontrolan atau pengaturan stres yang bertujuan untuk mengenal penyebab stres dan mengetahui teknik-teknik mengelola stres, sehingga seorang guru lebih baik dalam menguasai stres dalam kehidupan pribadinya dan dalam proses kegiatan mengajar disekolah dengan indikator seperti faktor lingkungan, beban kerja, kesempatan pengembangan karir, masalah peran, struktur dalam organisasi, hubungan interpersonal dan masalah pribadi.

\section{Adversity Quotient}

Defenisi operasional $A Q$ adalah kemampuan yang dimiliki individu dalam mengelola, mengatasi, dan merespon permasalahan di saat permasalahan itu muncul atau dengan kata lain kemampuan yang dimiliki seseorang untuk bertahan mengahadapi kesulitan atau hambatan, serta kemampuan seseorang dalam menghadapi perubahan yang terus 
terjadi dan menjadikan hambatan sebagai proses dalam mengembangkan diri serta potensi yang dimiliki dalam mencapai tujuan yang direncanakan.

Adversity Quotient adalah sesuatu potensi dimana dengan potensi ini seorang guru dapat mengubah hambatan menjadi peluang. Semakin tinggi Adversity Quotient seorang guru maka semakin tinggi pula keinginan untuk maju dan mengubah hambatan yang ada, tetapi sebaliknya semakin rendah Adversity Quotient seorang guru maka akan semakin mudah seorang guru itu menyerah dalam menghadapi hambatan atau kesulitan yang dihadapinya. Tinggi rendahnya Adversity Quotient seorang guru tersebut dapat diukur dengan indikator seperti Kendali diri, asal-usul /pengakuan, jangkauandan daya tahan.

\section{Spiritual Qoutient}

Kecerdasan spiritual dalam kamus Bahasa Indonesia, spiritual adalah halhal yang menyangkut nilai-nilai kemanusiaan yang bersifat non-materi terdapat dalam bingkaian dan terselubung dalam jiwa dan hati manusia seperti: kebaikan, kebenaran, keindahan, kesucian cinta, rohani dan kejiwaan. Spiritual Quotient adalah kemampuan individu atau seorang guru memaknai bagaimana arti dari kehidupan serta memahami nilai tersebut dari setiap perbuatan yang dilakukan dan kemampuan potensial setiap individu atau seorang guru yang menjadikan individu atau guru tersebut dapat menyadari dan menentukan makna, nilai, moral, serta cinta terhadap kekuatan yang lebih besar terhadap sesama makhluk hidup karena merasa sebagai bagian dari keseluruhan, sehingga membuat individu atau guru dapat menempatkan diri dan hidup lebih positif dengan penuh kebijaksanaan, kedamaian dan kebahagiaan yang hakiki. Untuk menentukan tinggi atau rendahnya Spiritual Quotient seorang guru bisa diukur dengan menggunakan indikator : Kemampuan bersikap fleksibel. Tingkat kesadaran diri, Kemampuan beradaptasi, Kemampuan menghadapi permasalahan, Kualitas hidup (visi dan misi), Keengganan untuk dirugikan, Kecenderungan untuk melihat (situasi dan kondisi) serta Kecenderungan untuk bertanya.

\section{METODOLOGI PENELITIAN}

Penelitian ini menguji tiga variabel yang akan diteliti dan untuk mengetahui ada tidaknya pengaruh antara variabel independen dengan variabel dependen. Sehubungan dengan ini maka yang menjadi variabel $\mathrm{X}_{1}$ (independen) adalah adversity quotient, variabel $\mathrm{X}_{2} \quad$ (independen) adalah spiritual quotient dan variabel $\mathrm{Y}$ (dependen) adalah manajemen stres kerja.

Populasi dalam penelitian ini adalah guru SMP Negeri Kecamatan Bangkinang kota jumlahnya 129 orang guru. Sampel dalam penelitian ini berjumlah 92 orang guru. Teknik yang digunakan dalam pengambilan sampel adalah dengan cara proportional random sampling.

Teknik pengumpulan data yang digunakan dalam penelitian ini adalah angket dengan menggunakan skala linkert. Adapun analisis data yang digunakan adalah analisis statistik deskriptif dan analisis statistik inferensial.

\section{HASIL PENELITIAN DAN PEMBAHASAN}

Dalam penelitian terdapat tiga hipotesis yang diuji secara inferensial dengan menggunakan teknik analisis regresi linier dan korelasi. Hipotesis pertama dan kedua diuji dengan teknik analisis regresi dan korelasi sederhana, sementara hipotesis ketiga diuji dengan 
teknik analisis regresi dan korelasi multiple.

\section{Pengujian Hipotesis Penelitian Pertama}

\begin{tabular}{|c|c|c|c|c|c|}
\hline \multirow[b]{2}{*}{ Model } & \multicolumn{2}{|c|}{$\begin{array}{c}\text { Unstandardized } \\
\text { Coefficients }\end{array}$} & \multirow{2}{*}{$\begin{array}{c}\begin{array}{c}\text { Standardized } \\
\text { Coefficients }\end{array} \\
\text { Beta }\end{array}$} & \multirow[b]{2}{*}{$\mathrm{t}$} & \multirow[b]{2}{*}{ Sig. } \\
\hline & B & Std. Error & & & \\
\hline 1 (Constant) & 29.578 & 7.085 & & 4.175 & .000 \\
\hline $\begin{array}{l}\text { Adversity } \\
\text { Quotient }\end{array}$ & 1.451 & .090 & .863 & 16.194 & .000 \\
\hline
\end{tabular}

Berdasarkan uji regresi linier sederhana dimana hasil persamaan regresi yang dihasilkan $\mathrm{Y}=29,578+$ $1,451 X_{1}$. Menjelaskan bahwa setiap peningkatan dari adversity quotient sebesar 1,451 dapat mempengaruhi manajemen stres kerja guru SMP Negeri di Kecamatan Bangkinang kota sebesar 1,451 dengan nilai konstanta sebesar 29,578.
Dengan demikian hipotesis nol ditolak karena thitung > ttabel $(16,194$ $>$ 1,987). Maka dapat disimpulkan bahwa Ho ditolak dan hipotesis alternatif diterima menjelaskan bahwa adversity quotient memiliki kontribusi terhadap manajemen stres kerja guru SMP Negeri di Kecamatan Bangkinang kota.

\section{Pengujian Korelasi Kontribusi Adversity Quotient Terhadap Manajemen Stres Kerja Guru SMP Negeri Di Kecamatan Bangkinang Kota}

\begin{tabular}{cccccc}
\hline Model & $\mathrm{R}$ & R Square & $\begin{array}{c}\text { Adjusted R } \\
\text { Square }\end{array}$ & $\begin{array}{c}\text { Std. Error of } \\
\text { the Estimate }\end{array}$ & $\begin{array}{c}\text { Durbin- } \\
\text { Watson }\end{array}$ \\
\hline 1 & $.863^{\mathrm{a}}$ & .744 & .742 & 12.01388 & 1.848 \\
\hline
\end{tabular}

Nilai koefisien determinasi yang dihasilkan sebesar 0,744, hasil ini menjelaskan bahwa besarnya kontribusi adversity quotient terhadap manajemen stres kerja sebesar $74,4 \%$ dan sisanya $25,6 \%$ dipengaruhi oleh variabel lain yang tidak diteliti dalam penelitian ini. 


\section{Pengujian Hipotesis Penelitian Kedua}

Pengujian Hipotesis Kedua Mengenai Kontribusi Spiritual Quotient Terhadap Manajemen Stres Kerja Guru SMP Negeri Di Kecamatan Bangkinang Kota

\begin{tabular}{|c|c|c|c|c|c|}
\hline \multirow[b]{2}{*}{ Model } & \multicolumn{2}{|c|}{$\begin{array}{c}\text { Unstandardized } \\
\text { Coefficients }\end{array}$} & \multirow{2}{*}{$\begin{array}{c}\text { Standardized } \\
\text { Coefficients }\end{array}$} & \multirow[b]{2}{*}{$\mathrm{t}$} & \multirow[b]{2}{*}{ Sig. } \\
\hline & B & Std. Error & & & \\
\hline 1 (Constant) & 32.244 & 7.088 & & 4.549 & .000 \\
\hline $\begin{array}{l}\text { Spiritual } \\
\text { Quotient }\end{array}$ & .891 & .056 & .858 & 15.814 & .000 \\
\hline
\end{tabular}

Berdasarkan uji regresi linier sederhana dimana hasil persamaan regresi yang dihasilkan $\mathrm{Y}=32,244+$ $0,891 X_{2}$. Menjelaskan bahwa setiap peningkatan dari spiritual quotient sebesar 0,891 dapat mempengaruhi manajemen stres kerja guru SMP Negeri di Kecamatan Bangkinang kota sebesar 0,891 dengan nilai konstanta sebesar 32,244.
Dengan demikian hipotesis nol ditolak karena thitung $>$ ttabel $(15,814$ $>$ 1,987). Maka dapat disimpulkan bahwa Ho ditolak dan hipotesis alternatif diterima menjelaskan bahwa spiritual quotient memiliki kontribusi terhadap manajemen stres kerja guru SMP Negeri di Kecamatan Bangkinang kota.

\section{Pengujian Korelasi Kontribusi Spiritual Quotient Terhadap Manajemen Stres Kerja Guru SMP Negeri Di Kecamatan Bangkinang Kota}

\begin{tabular}{cccccc}
\hline Model & $\mathrm{R}$ & R Square & $\begin{array}{c}\text { Adjusted R } \\
\text { Square }\end{array}$ & $\begin{array}{c}\text { Std. Error of } \\
\text { the Estimate }\end{array}$ & $\begin{array}{c}\text { Durbin- } \\
\text { Watson }\end{array}$ \\
\hline 1 & $.858^{\mathrm{a}}$ & .735 & .732 & 12.22712 & 1.587 \\
\hline
\end{tabular}

Nilai koefisien determinasi yang dihasilkan sebesar 0,735 , hasil ini menjelaskan bahwa besarnya kontribusi spiritual quotient terhadap manajemen stres kerja sebesar 73,5\% dan sisanya $26,5 \%$ dipengaruhi oleh variabel lain yang tidak diteliti dalam penelitian ini. 


\section{Pengujian Hipotesis Penelitian Ketiga}

\begin{tabular}{|c|c|c|c|c|c|c|}
\hline \multirow{2}{*}{\multicolumn{2}{|c|}{ Model }} & \multicolumn{2}{|c|}{$\begin{array}{c}\text { Unstandardized } \\
\text { Coefficients }\end{array}$} & \multirow{2}{*}{$\begin{array}{c}\begin{array}{c}\text { Standardized } \\
\text { Coefficients }\end{array} \\
\text { Beta }\end{array}$} & \multirow[b]{2}{*}{$\mathrm{t}$} & \multirow[b]{2}{*}{ Sig. } \\
\hline & & B & Std. Error & & & \\
\hline \multirow[t]{3}{*}{1} & (Constant) & 27.524 & 6.924 & & 3.975 & .000 \\
\hline & $\begin{array}{l}\text { Adversity } \\
\text { Quotient }\end{array}$ & .823 & .261 & .489 & 3.153 & .002 \\
\hline & $\begin{array}{l}\text { Spiritual } \\
\text { Quotient }\end{array}$ & .412 & .161 & .396 & 2.553 & .012 \\
\hline
\end{tabular}

Berdasarkan uji regresi linier berganda dimana hasil persamaan regresi yang dihasilkan $\mathrm{Y}=27,524+$ $0,823 X_{1}+0,412 X_{2}$. Menjelaskan bahwa setiap peningkatan dari adversity quotient sebesar 0,823 dapat mempengaruhi manajemen stres kerja guru SMP Negeri di Kecamatan
Bangkinang kota sebesar 82,3\%, sementara setiap peningkatan dari spiritual quotient sebesar 0,412 dapat mempengaruhi manajemen stres kerja guru SMP Negeri di Kecamatan Bangkinang kota sebesar $41,2 \%$ dengan nilai konstanta sebesar 12,378.

Pengujian Hipotesis Ketiga Mengenai Kontribusi Adversity Quotient Dan Spiritual Quotient Terhadap Manajemen Stres Kerja Guru SMP Negeri Di Kecamatan Bangkinang Kota

\begin{tabular}{|c|c|c|c|c|c|c|}
\hline \multicolumn{2}{|c|}{ Model } & \multirow{2}{*}{$\begin{array}{c}\begin{array}{l}\text { Sum of } \\
\text { Squares }\end{array} \\
38737.390\end{array}$} & \multirow{2}{*}{$\frac{\mathrm{df}}{2}$} & \multirow{2}{*}{$\begin{array}{r}\text { Mean Square } \\
19368.695\end{array}$} & \multirow{2}{*}{$\frac{F}{142.421}$} & \multirow{2}{*}{$\frac{\text { Sig. }}{.000^{\mathrm{a}}}$} \\
\hline 1 & Regression & & & & & \\
\hline & Residual & 12103.610 & 89 & 135.996 & & \\
\hline & Total & 50841.000 & 91 & & & \\
\hline
\end{tabular}

Dengan demikian hipotesis nol ditolak karena thitung $>$ ttabel $(142,421$ > 3,94). Maka dapat disimpulkan bahwa Ho ditolah dan hipotesis alternatif diterima menjelaskan bahwa adversity quotient dan spiritual quotient memiliki kontribusi terhadap manajemen stres kerja guru SMP Negeri di Kecamatan Bangkinang kota.

Pengujian Korelasi Kontribusi Adversity Quotient Dan Spiritual Quotient Terhadap Manajemen Stres Kerja Guru SMP Negeri Di Kecamatan Bangkinang Kota

\begin{tabular}{cccccc}
\hline Model & $R$ & $R$ Square & $\begin{array}{c}\text { Adjusted } R \\
\text { Square }\end{array}$ & $\begin{array}{c}\text { Std. Error of } \\
\text { the Estimate }\end{array}$ & $\begin{array}{c}\text { Durbin- } \\
\text { Watson }\end{array}$ \\
\hline 1 & $.873^{\mathrm{a}}$ & .762 & .757 & 11.66172 & 1.696 \\
\hline
\end{tabular}


Nilai koefisien determinasi yang dihasilkan sebesar 0,762, hasil ini menjelaskan bahwa besarnya kontribusi adversity quotient dan spiritual quotient terhadap manajemen stres kerja sebesar $76,2 \%$ dan sisanya $23,8 \%$ dipengaruhi oleh variabel lain yang tidak diteliti dalam penelitian ini.

\section{SIMPULAN, IMPLIKASI DAN SARAN}

Berdasarkan hasil penelitian yang telah dilaksanakan, dimana kesimpulan didalam penelitian ini adalah sebagai berikut : 1) Secara parsial adversity quotient memiliki kontribusi terhadap manajemen stres kerja guru. 2) Secara parsial spiritual quotient memiliki kontribusi terhadap manajemen stres kerja guru. 3) Secara simultan adversity quotient dan spiritual quotient memiliki kontribusi terhadap manajemen stres kerja guru.

Berdasarkan hasil penelitian dengan memperhatikan fakta-fakta yang terjadi dilapangan dapat dikemukakan bahwa terdapat pengaruh antara adversity quotient dan spiritual quotient terhadap manajemen stres kerja guru SMP Negeri di Kecamatan Bangkinang kota. Bertolak dari hasil temuan diatas, maka implikasi hasil penelitian ini akan diarahkan kepada upaya pengelolaan manajemen stres melalui variabel adversity quotient dan spiritual quotient

Hasil penelitian yang telah dilaksanakan sebaiknya kepada pihak SMP Negeri Dikecamatan Bangkinang Kota agar dapat menciptakan lingkungan kerja aman dan membangun hubungan kerja yang baik terhadap setiap guru dan kepala sekolah sehingga dapat membentuk kerja sama yang baik didalam bekerja. Kepada kepala sekolah SMP Negeri Dikecamatan Bangkinang kota agar dapat memberikan arahan dan mengelola pemberian pekerjaan untuk mengurangi timbulnya stres dalam bekerja. Disarankan kepada setiap Guru di SMP Negeri Dikecamatan Bangkinang Kota meningkatkan kemampuan yang dimiliki, terutama kemampuan didalam mengelola setiap permasalahan yang terjadi dan dengan cepat dapat mengambil keputusan.

\section{DAFTAR PUSTAKA}

Ali Muklasin., (2013), Pengembangan kecerdasan spiritual dalam meningkatkan sumber daya guru,dalam Jurnal Universitas Islam Negeri Maulana Malik Ibrahim , Malang.

Anatan, Lina. \& Lena Elitan., (2009), Manajemen Sumber Daya Manusia Dalam bisnis Modern, Alfabeta, Bandung.

Anwar Prabu Mangkunegara, Mela Puspita Sari, (2015), Kecerdasan Emosi Guru, Stres Kerja dan Kinerja Guru SMA , Jurnal Kependidikan Penelitian Inovasi Pembelajaran, Vol 45 No 2, 2015, UNY.

Baharuddin dan Rahmatia Zakaria., (2018) Pengaruh Kecerdasan Spritual Terhadap Peningkatan Kinerja Guru di SMA Negeri 3 Takalar Jurnal Idaarah, Vol. 2, NO 1, JUNI 2018, Fakultas Tarbiyah dan Keguruan UIN Alauddin, Makassar.

Devi Risma, (2016), Analisis Self Recilience Dalam Menyelesaikan Skripsi pada Mahasiswa Prodi PG Paud FKIP Universitas Riau, dalam Jurnal Vol 5, NO 12016 , Universitas Riau.

Esa Nur Wahyuni dan Khairul Bariyyah, 2019/6/30, Apakah spiritualitas 
berkontribusi terhadap kesehatan mental mahasiswa?,dalam jurnal Educatio Vol 5 No 1 2019, Universitas Islam Negeri Maulana Malik Ibrahim, Malang.

Ida Nur Hidayati, Margono Setiawan, (2013), Kecerdasan Emosional dan Kecerdasan Spiritual Pengaruhnya Terhadap Kepuasan Kerja dan Kinerja Karyawan, dalam Jurnal Aplikasi Manajemen 11, Vol 4, LPMP , Nusa Tenggara Barat.

Keith Davis, Jhon W. (1985), Perilaku dalam Organisasi, Erlangga, Jakarta

Martini Jamaris, (2013). Orientasi Baru dalam Psikologi Pendidikan. Ghalia Indonesia, Bogor.

Nyoman Sukardewi, Nyoman Dantes, Nyoman Natajaya., (2013), Kontribusi Adversity Quotient (AQ), etos kerja, dan budaya organisasi terhadap kinerja guru SMA Negeri Kosma di kota Amlapura, e-Journal Program Pascasarjana Universitas Pendidikan Ganesha, Volume 4 tahun 2013, Program Studi Administrasi Pendidikan, Singaraja Indonesia.

P, Dwi Sunar., (2010) Edisi Lengkap Tes $I Q$, EQ, Dan SQ Cara Mudah Mengenali Dan Memaknai Kepribadian, Jogjakarta.

Riduwan, Engkos Achmad Kuncoro., (2012), Cara menggunakan dan memaknai path analysis (analisis jalur), Alfabeta,Bandung.

Rivai V, Mulyadi D., (2011), Kepemimpinan dan perilaku organisasi., Rajawali pers Jakarta.
Sopiatin,dan Sohari Sahrani., (2011), Psikologi dalam Perspektif Islam, Ghalia Indonesia Bogor.

Stephen P. Robbins Timothy AJ, (2011). Perilaku Organisasi. Salemba Empat, Jakarta.

Stoltz, P G. (2005)., Adversity Quotient : Mengubah Hambatan Menjadi Peluang, PT Gramedia Widiasarna Indonesia, Jakarta.

Sugiyono, (2014). Cara Mudah Menyusun Skripsi, Tesis, dan Disertasi. Alfabeta, Bandung.

Tarwaka., (2015). Ergonomi Industri Dasar-Dasar Pengetahuan Ergonomi Dan Aplikasi di Tempat Kerja. Harapan Press Surakarta.

Wigglesworth, Cindy . J. Neal (ed.), (2013) Handbook of Faith and Spirituality in the Workplace: Emerging 441 Research and Practice. Springer Science+Business Media New York. 